\title{
Design and Implementation of IGBT based Static Excitation System with Buck Converter
}

\author{
Tanmay Mishra, Student Member, IEEE, Gurunath Gurrala, Senior Member, IEEE \\ Deparment of Electrical Engineering, Indian Institute of Science Bangalore \\ tanmaym@iisc.ac.in, gurunath@iisc.ac.in
}

\begin{abstract}
This paper presents the development of a DCDC buck converter based static excitation system for a microalternator. The IGBT based AC to DC converter is used as Front End Converter (FEC) followed by a buck converter to control the field voltage of micro-alternator. TMS320F28377S microcontroller is used for digital implementation of the Automatic Voltage Regulator (AVR). A proportional integral(PI) controller is used in the AVR. The proposed system is tested under various small and large disturbances like change in the reference voltage, 3phase fault at generator terminal, and sudden load rejection to study the performance of the proposed excitation system.
\end{abstract}

Index Terms-Micro-alternator, Static excitation system, buck converter, Automatic voltage regulator.

\section{INTRODUCTION}

The excitation system for a synchronous machine is meant to supply the required field current to its field winding [1]. The terminal voltage of the generator proportionally depends on field voltage and current. The field winding needs to be supplied from a DC source. Various models of excitation systems are used to supply the DC power to the field winding, namely, DC excitation system, AC excitation system, and static excitation system. Out of the various types of the excitation systems, static excitation system is the most popular one because of its fast response and high ceiling voltage. Due to the faster response of the excitation system, the transient stability of the power system network gets improved. Since the 1960s, the trend of thyristor-based static excitation system has been started. The main components of a static excitation system are control circuit and power electronics based converter to supply the DC power to the alternator field winding. It also performs protection, control and regulating action which leads to the satisfactory performance of the power system [1]. In 1961, silicon rectifier diode based static excitation systems were developed for steam turbine generator [2].

The excitation control system consists of an automatic voltage regulator (AVR) and an exciter as shown in Fig. 1. The function of AVR is to keep the terminal voltage of the generator at the desired level. The sensed, and then filtered terminal voltage RMS value is fed to AVR. When AVR senses the low alternator terminal voltage, the field current increases; while, in the case of increase in the terminal voltage, the field

This work is supported by Fund for Improvement of Science and Technology (FIST) program, DST, India, No.SR/FST/ETII-063/2015 (C) and (G).

978-1-5386-9316-2/18/\$31.00 @ 2018 IEEE

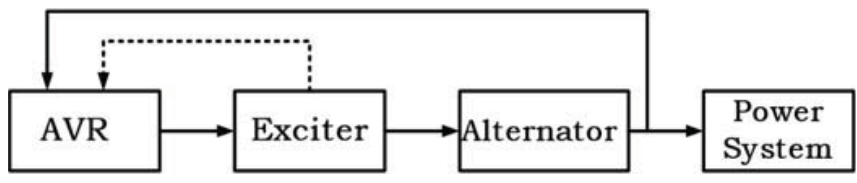

Fig. 1: Block diagram of the excitation sytem

current decreases. Any disturbance in the terminal voltage will generate an error signal, which substantially modifies the firing gate pulses to the converter [3]. Another important purpose of AVR is to increase the transient stability of the alternator by driving excitation voltage to the ceiling under transient conditions. To increase the transient stability limit, a fastacting high gain AVR is desirable [4]. The traditional static excitation system consists of a bridge rectifier, connected to the generator terminals through a potential step down transformer, and the firing pulses are controlled via AVR. These kinds of exciters suffer under fault conditions at generator terminal, as the input supply to the exciter is coming from the generator terminal, which leads to transient instability.

The thyristor-based static excitation system has many issues like current distortion, voltage notching and unacceptable field forcing capability under abnormal conditions [5]. The development of power electronics devices leads to the usage of new switching devices like Insulated-Gate Bipolar Transistors (IGBT) in the static excitation system. In the meantime, power MOSFET based chopper driven exciters were used to overcome the shortcomings of the thyristor-based static exciters, but it failed due to the lack of high voltage and current handling capabilities [6]. In recent years, IGBT based converters are used in industrial utilities due to better performance during switching, higher current, and voltage handling capabilities. In [7], the boost-buck converter based static excitation system is implemented to enhance the field forcing capability. The boost-buck excitation system is similar to the traditional static excitation systems, with an addition of a boost-buck converter for purpose of enhancing the excitation system input voltage. The stability of this system is better than the static excitation system, and also the performance is robust. Achieving fast system response as per IEEE 421.2 standard for fast acting excitation systems becomes challenging due to the presence of non-minimum phase zero in the transfer function of the boost-buck converter [8].

In [5], another excitation system model is described similar 
to a conventional static excitation system having voltage source converter with DC to DC chopper connected to the field winding of the excitation system. Here, Reactive power can also be regulated between the converter and the grid. The output of H-bridge chopper, in this case, is pulsating due to lack of proper filtering, which needs to be rectified.

In this paper, a buck converter based excitation system is developed. A Proportional Integral (PI) controller is used to achieve automatic voltage regulation meeting the specifications of IEEE 421.2 standard [6]. The PI controller is designed to enhance the bandwidth of the system for a faster response. For tunning the controller, an offline or no-load model of the generator is taken. The offline model can be represented by first-order transfer function with only generator field winding time constant.

\section{SYSTEM DESCRIPTION}

The system considered here contains a standalone microalternator with 3-phase RLC load bank. There are various permutations and combinations available in the load bank to vary power factor from 0.8 lag to 0.8 lead. Fig. 2 shows the overall system setup. Here, 3rd order IEEE 1.0 model having the 3-phase star connected winding on stator and DC field winding on the rotor is considered for control design. The field winding is energized by the proposed excitation system described in the following subsections :

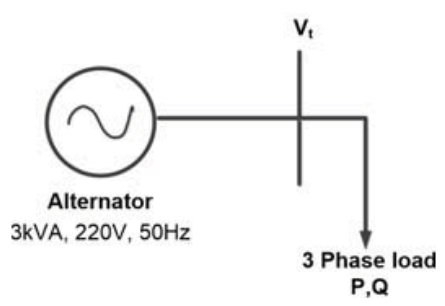

Fig. 2: Loaded generator

\section{A. Proposed excitation system}

The excitation system consists of a 3-phase front-end AC to DC front end converter (FEC) followed by a buck converter as shown in Fig. 3. The input terminals of FEC are connected to lab mains through an autotransformer for the field flashing, and the output terminals are connected to the input of the buck converter. The output terminals of the buck converter are connected to the field winding of the alternator through LC smoothing filter. The synchronous machine is driven by a DC machine. Terminal voltage and rotor speed are sensed through a voltage sensor card, based on the differential operational amplifier. Both quantities are then fed to the TMS320F28377S microcontroller through ADC channels. Further, a PI controller is used to minimize the error between the reference voltage and terminal voltage. The control signal is fed to the PWM module of the microcontroller to generate the required PWM signal of $5 \mathrm{kHz}$ switching frequency for the IGBTs of the buck converter. LM339 Quad Differential Comparator is used for shifting the level of PWM signal from $(0-3) \mathrm{V}$ to $(0-15) \mathrm{V}$. The

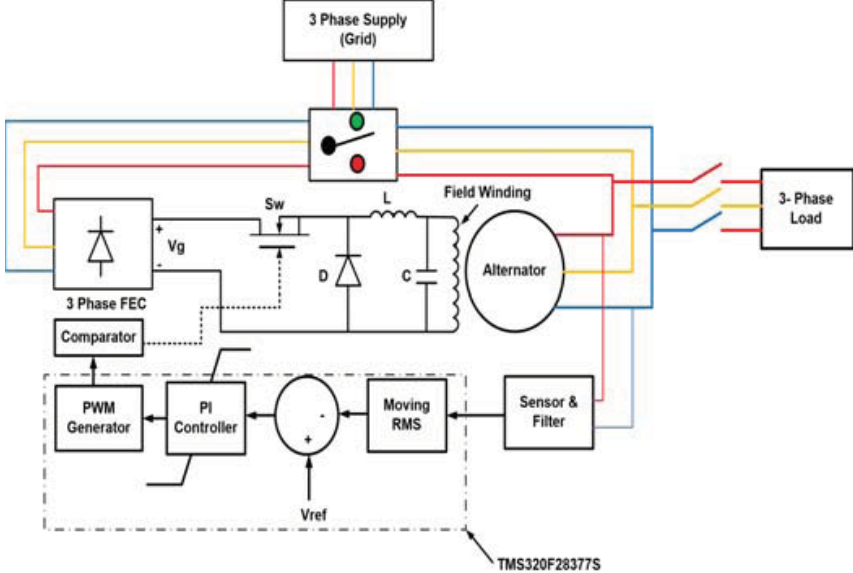

Fig. 3: Block diagram of Experimental setup for proposed excitation control system

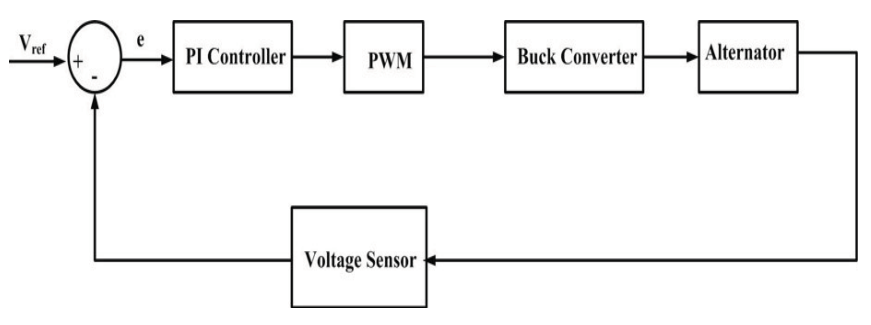

Fig. 4: Block diagram of proposed system

small signal modeling of the buck converter and generator is required to tune the PI controller. The block diagram of the proposed excitation system can be shown as Fig. 4.

\section{B. Synchronous generator}

When the generator is connected to the load or external power system, the transfer function $G_{g e n}(\mathrm{~s})$ includes the dynamics associated with the external power system. Excitation system is usually designed with generator under no-load [8] and tested under loading conditions. Consider the IEEE 1.0 generator model, d-axis flux linkage equation,

$$
\begin{gathered}
\frac{d E_{q}^{\prime}}{d t}=\frac{-E_{q}^{\prime}+\left(x_{d}-x^{\prime} d\right) i_{d}+E_{f}}{T_{d o}^{\prime}} \\
v_{t}=v_{q}+j v_{d}=\left(E_{q}^{\prime}+x_{d}^{\prime} i_{d}\right)+j\left(-x_{d} i_{q}\right)
\end{gathered}
$$

For no load condition, $i_{d}=i_{q}=0$ and $E_{q}^{\prime}=v_{t}$

$$
\begin{gathered}
\frac{d v_{t}}{d t}=\frac{-v_{t}+E_{f}}{T_{d o}^{\prime}} \\
\frac{V_{t}(s)}{E_{f}(s)}=\frac{1}{1+s T_{d o}^{\prime}}
\end{gathered}
$$

where, $V_{t}$ is terminal voltage of alternator, $E_{q}^{\prime}$ is the q-axis component of the voltage behind transient reactance $x_{d}^{\prime} . i_{d}, i_{q}$ are d-axis and q-axis stator currents respectively, $T_{d o}^{\prime}$ is open circuit $\mathrm{d}$-axis transient time constant. 


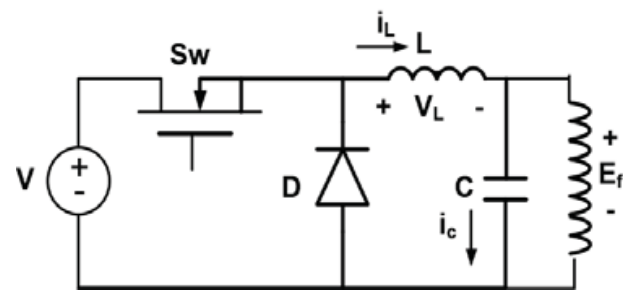

Fig. 5: Buck Converter

\section{Buck converter based excitation system}

In Fig. 5 the buck converter is shown. The relation between DC link voltage $\mathrm{V}$, acting as an input voltage source to the buck converter and the field voltage $\mathrm{E}_{f}$, supplied to excite the field winding of the alternator with duty cycle $d$ and switching frequency of PWM signal $\mathrm{f}_{s}$ is given as, [9] :

$$
\begin{aligned}
& E_{f}=d . V \\
& d=T_{\text {on }} \cdot f_{s}
\end{aligned}
$$

where $T_{\text {on }}$ is the total turn-on time of IGBT for one period. When the switch is on,

$$
\begin{gathered}
v_{L}(t)=L \frac{d i_{L}}{d t}=v(t)-e_{f}(t) \\
i_{c}(t)=i_{L}(t)-i_{0}(t)
\end{gathered}
$$

When the switch is off,

$$
\begin{gathered}
v_{L}(t)=L \frac{d i_{L}}{d t}=-e_{f}(t) \\
i_{c}(t)=i_{L}(t)-i_{0}(t)
\end{gathered}
$$

Using small ripple approximation and averaging the $v_{L}$ and $i_{c}$ for one switching cycle,

$$
\begin{gathered}
\left\langle v_{L}(t)\right\rangle=d(t)\left\langle v(t)-e_{f}(t)\right\rangle_{T_{s}}-d^{\prime}(t)\left\langle-e_{f}(t)\right\rangle_{T_{s}} \\
\left\langle i_{c}(t)\right\rangle=\left\langle i_{L}(t)-i_{0}(t)\right\rangle_{T_{s}}
\end{gathered}
$$

Introducing small perturbation,

$$
\begin{gathered}
d(t)=D+\tilde{d}(t) \\
v(t)=V+\tilde{v}(t) \\
e_{f}(t)=E_{f}+\tilde{e}_{f}(t) \\
i_{c}(t)=I_{0}+\tilde{i}_{c}(t)
\end{gathered}
$$

Neglecting DC quantities and very small terms,

$$
\begin{gathered}
L \frac{d \tilde{i}_{L}(t)}{d t}=\tilde{d}(t) V+D \tilde{v}(t)-\tilde{e}_{f}(t) \\
c \frac{d \tilde{v}_{c}(t)}{d t}=\tilde{i}_{L}-\left(\tilde{e}_{f}(t) / r_{f}\right)
\end{gathered}
$$

Taking the Laplace transform and neglecting the variation in DC bus voltage i.e. $\tilde{v}(t)=0$, the control to output transfer function is given by,

$$
\frac{\Delta E_{f}(s)}{\Delta d(s)}=\frac{V}{1+\frac{L}{r_{f}} s+L C s^{2}}
$$

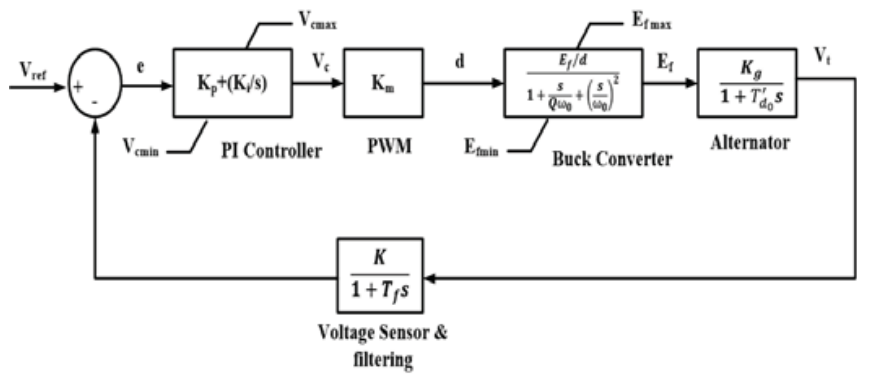

Fig. 6: Control structure of complete excitation system

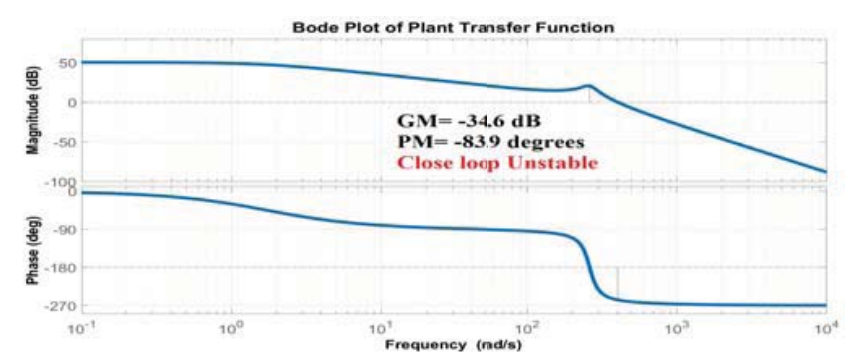

(a)

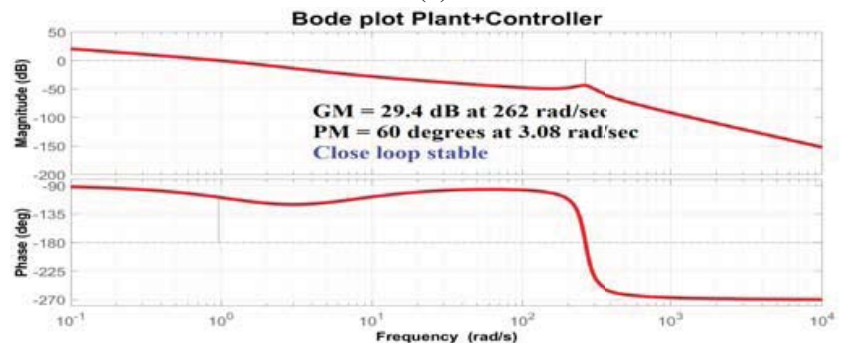

(b)

Fig. 7: Bode plots for (a) excitation system(plant), (b) Bode plot of excitation system with designed controller

In general, the control to output transfer function for the buck converter is given by,

$$
\frac{\Delta E_{f}(s)}{\Delta d(s)}=\frac{e_{f} / d}{1+\frac{s}{Q \omega_{0}}+\frac{s^{2}}{\omega^{2}}}
$$

The quality factor $\mathrm{Q}$ is given by $r_{f} \sqrt{\frac{C}{L}}$ and the natural frequency $\omega_{0}$ is given by $\frac{1}{\sqrt{L C}}$, where $r_{f}$ is field winding resistance, $\mathrm{L}$ is smoothening filter inductor, and $\mathrm{C}$ is smoothening filter capacitor.

\section{Controller Design}

In the switching converters, $E_{f}$ depends upon $V_{g}$ and $d$. The controller will change the duty as per the error fed to it. The complete control block diagram is shown in Fig. 6. The controller, in this case, has to enhance the bandwidth of the overall system for a faster response under abnormal conditions without migrating to an unstable region. At the same time, it should comply with IEEE 421.2 standard [11]. As per the standard, gain margin should be greater than $6 \mathrm{~dB}$, phase margin should be in between $20^{\circ}-80^{\circ}$ and bandwidth should 
be in the range of $(0.3-5) \mathrm{Hz}$. The load regulation of the system should be within $0.5 \%$ band-limit under steady state and the overshoot needs to be between $(0-40) \%$ to satisfy the small signal dynamic performance.

Plant and controller transfer function is given by $\mathrm{P}(\mathrm{s})$ and

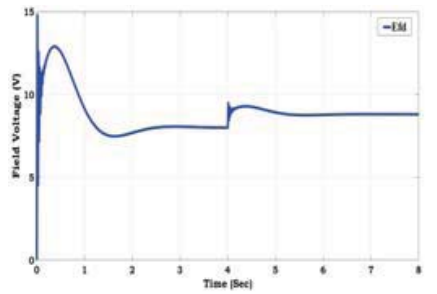

(a)

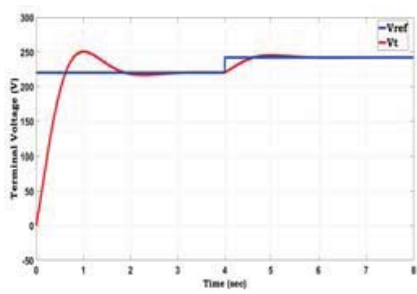

(b)
Fig. 8: Simulation results for for $10 \%$ change in $V_{\text {ref }}$ (a) Field voltage $E_{f}$, (b) terminal voltage $V_{t}$

$\mathrm{C}(\mathrm{s})$ respectively:

$$
\begin{gathered}
P(s)=\frac{1650}{8.413 \times 10^{-} 05 s^{3}+0.000463 s^{2}+0.5782 s+1} \\
C(s)=K \frac{T s+1}{s}
\end{gathered}
$$

Open loop transfer function,

$$
G(s)=K \frac{T s+1}{s} \times P(S)
$$

where $\mathrm{T}=K_{p} / K_{i}$ and $\mathrm{K}=K_{i}$. Selecting the $\mathrm{T}$ value so that it will cancel out one of the pole of $\mathrm{P}(\mathrm{s})$, which is $\mathrm{T}=0.5776$. Now G(s) can be written as,

$$
\begin{aligned}
G(s) & =\frac{K}{s} \times \frac{1650}{1.4564 \times 10^{-} 04 s^{2}+5.013 \times 10^{-04 s+1}} \\
G(j \omega) & =\frac{K}{j \omega} \times \frac{1650}{\left(1-1.4564 \times 10^{-} 04 \omega^{2}\right)+j 5.013 \times 10^{-} 04 \omega}
\end{aligned}
$$

$|G(j \omega)|=1$ at gain cross over frequency, $\angle G(j \omega)=-120^{\circ}$ for the Phase margin (PM) of $60^{\circ}$ at gain crossover frequency.

For gain $\mathrm{K}=0.003269$, PM of 60 degrees was achieved for $G(j \omega)$ i.e. giving the phase as $-120^{\circ}$ at the gain crossover frequency. Fig. $7 \mathrm{a}$ and $7 \mathrm{~b}$ show the bode plots of open loop exciter (plant) and closed-loop system with controller. This method of pole-zero cancellation, minimizes the maximum overshoot of the overall control system [10]. The uncontrolled plant was clearly unstable with both PM and gain margin (GM) being negative. With proper tuning of PI controller, the GM increased to $29.4 \mathrm{~dB}$ while keeping $\mathrm{PM}$ at $60^{\circ}$. The bandwidth of the system is $0.53 \mathrm{~Hz}$, which is within the limits as per IEEE std. 421.2. Taking the controller parameters, simulation was performed for $10 \%$ change in $V_{\text {ref }}$. The results are shown in Fig. 8a and 8b. The overshoot in $V_{t}$ was $13.63 \%$ which is within the limits as per IEEE 421.2 std.

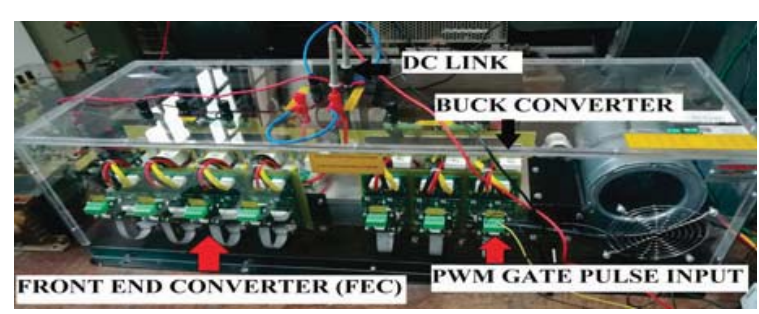

(a)

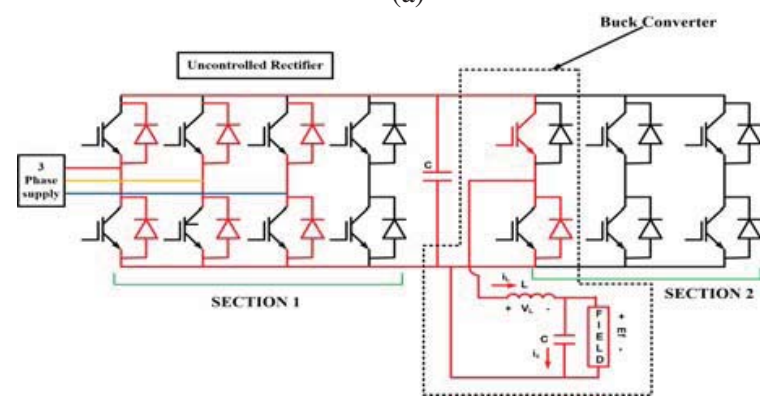

(b)

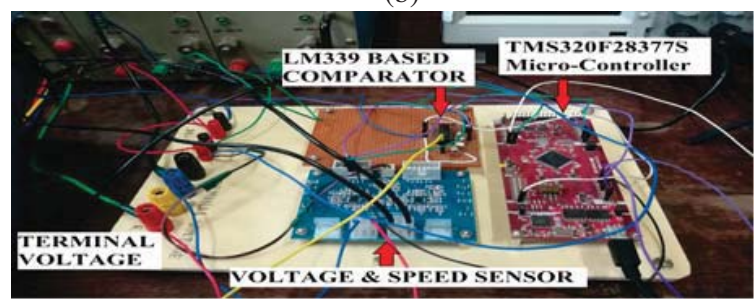

(c)

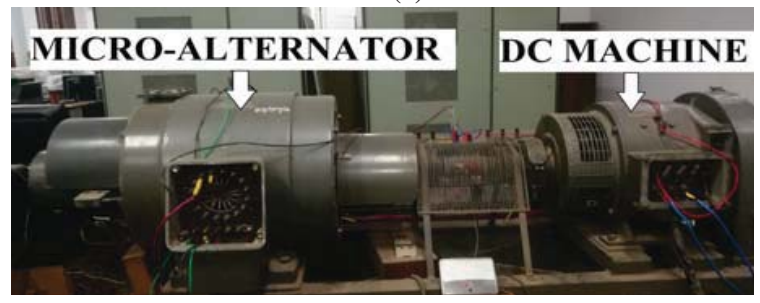

(d)

Fig. 9: Hardware setup (a) exciter and FEC, (b) connection of 7-leg converter as FEC and buck converter, (c)Automatic voltage regulator (AVR), (d) micro-machine

\section{EXPERIMENTAL RESULTS}

\section{A. Hardware description}

The experimental set up of exciter and FEC are shown in Fig. 9a. A 7-leg semikron converter was modified to work as FEC and exciter, the connection for the same is shown in Fig. 9b. There are two sections in this 7-leg converter. Section 1 was acting as the FEC, while section 2 was modified as buck converter based exciter. A DC bus capacitor of $4700 \mu \mathrm{F}$ was used to connect the section 1 and 2 . In section 1 , out of four legs the first three legs were used as an uncontrolled bridge rectifier. The 3 phase input to the bridge rectifier can be given either from the auxiliary supply during field flashing or directly from the generator terminals. In section 2 , any one of the three legs can be used for the buck converter. Here, 
for buck converter one IGBT based switch, and a diode are needed; which can be achieved by firing only one switch in one particular leg. The other unfired switch can be used as a diode. The PWM pulse given to fire the IGBT switch is of $(0-15) \mathrm{V}$ level provided by the AVR.

The AVR with micro-controller and micro-alternator are shown in Fig. 9c and Fig. 9d respectively. In AVR, sinusoidal $\mathrm{R}$ and $\mathrm{Y}$ phase voltages were taken from the generator terminal and were then fed back to the voltage sensor card which scaled down the $230 \mathrm{~V}$ line to line voltage into $(0-3) \mathrm{V}$, which included the DC offset of $1.5 \mathrm{~V}$. The output of the voltage sensor card was given to TMS320F28377S micro-controller's ADC channel having acquisition duration or sample window of 500ns which is 100 times of the system clock. The moving RMS calculated for 100 samples was then compared with the $V_{\text {ref }}$. The error between the $V_{\text {ref }}$ and the $V_{t}$ was given to the PI controller. PI controller was implemented with the forward Euler approach. To avoid the accumulation of error, the antiwindup was incorporated. The output of the PI controller $V_{\text {con }}$ was fed to the ePWM module, former was then compared with the ramp signal and latter generated the required PWM signal. The generated (0-3)V PWM was not adequate to fire the converter. So, it was conditioned properly to $(0-15) \mathrm{V}$ level. LM339 based comparator was used for conditioning the PWM signal up to $(0-15) \mathrm{V}$.

The micro-machine consists of a micro-alternator coupled with DC motor. The DC motor was used as the prime mover for the micro-alternator with speed of 1500rpm. The field and armature winding of DC motor were energized using a bridge rectifier and 3-phase supply coming from the grid. The parameters of exciter and alternator are given in Table I and Table II respectively.

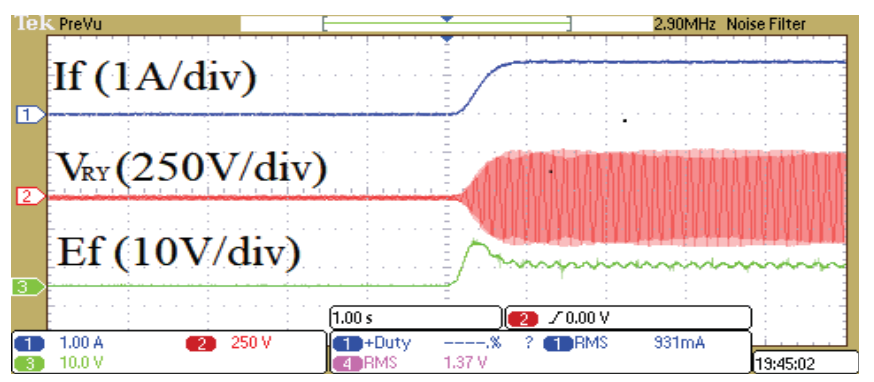

Fig. 10: Experimental result: Voltage build up

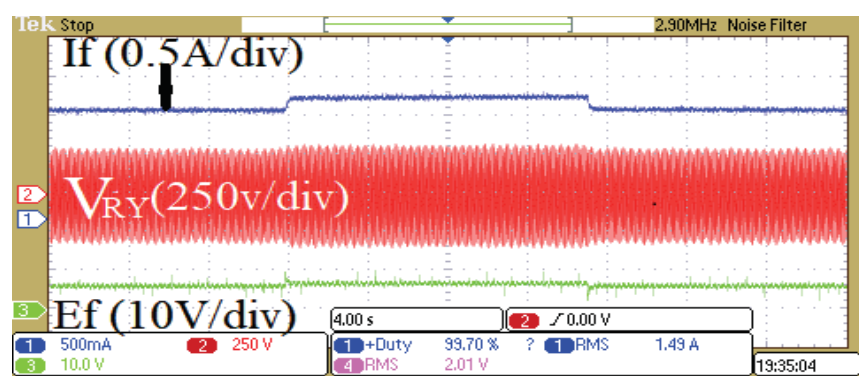

Fig. 11: Experimental result: $10 \%$ change in $V_{r e f}$

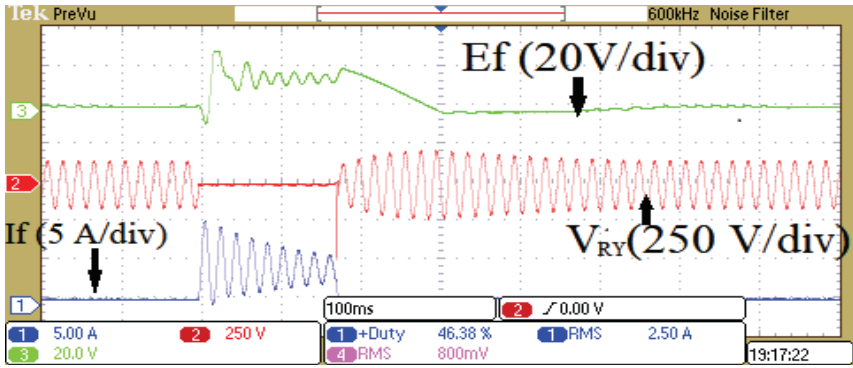

Fig. 12: Experimental result: 3- $\phi$ fault at generator terminal B. Results

The proposed system was exposed to disturbances like 3phase fault at generator terminal, $10 \%$ change in $V_{\text {ref }}$, sudden addition of load, and load rejection.

- Voltage buildup: Fig. 10 shows field current, field voltage, and line to line voltage between R-phase and Y-phase $\left(V_{R Y}\right)$ during voltage buildup of the alternator, the rise time of $0.7 \mathrm{~s}$ was observed. As per IEEE 421.2 std the rise time should be between $0.025 \mathrm{~s}$ to $2.5 \mathrm{~s}$ [11]. The time constant $T_{d o}^{\prime}$ to reach the $63.21 \%$ of the rated voltage observed as $0.5775 \mathrm{~s}$. The settling time to reach the steady state voltage within $0.5 \%$ voltage regulation was $1.25 \mathrm{~s}$, which is within the standard limits given by $(0.2-10) \mathrm{s}$ in IEEE 421.2 std [11].

- $10 \%$ change in $V_{\text {ref: }}$ In Fig. 11, field current, field voltage, and $V_{R Y}$ are shown for $10 \%$ step change in reference voltage. The reference voltage was first changed to $242 \mathrm{~V}$ from $220 \mathrm{~V}$ and then again reduced to $220 \mathrm{~V}$. It took $0.2 \mathrm{~s}$ to settle down to the steady state value of rated line to line voltage and field current increased to $1.6 \mathrm{~A}$ from $1.4 \mathrm{~A}$ in the same duration.

- 3- $\phi$ fault at generator terminal: Fig. 12 shows field current, field voltage, and $V_{R Y}$, during 3-phase fault at generator terminal with $50 \%$ of rated voltage. The field current hit the limit (10 times the no-load field current), and field voltage also hit its maximum limit (7 times the no-load field voltage), which shows the field forcing capability. The short circuit was applied for $165 \mathrm{~ms}$ or 8 cycles.

- Sudden application of load: The system was tested under various load conditions. The steady state no-load line to line voltage at the generator terminal was $220 \mathrm{~V}$ before applying the loads. In Fig. 13a with 500W+120 Var (capacitive) load, the terminal voltage almost remained constant, with slight glitch in field current and field voltage at the point of disturbance. During leading pf load, some variation in the phase of the terminal voltage was observed due to capacitive load. In Fig. 13b, 1000W load was suddenly applied to the generator terminal and the terminal voltage immediately dropped to $198 \mathrm{~V}$ from $220 \mathrm{~V}$ and it reached to $212 \mathrm{~V}$ at steady state, which is $3.63 \%$ drop of the rated value.

- Load rejection: Load rejection is one of the important experiment to test the performance of the system. Here, the system was tested under two load rejection cases. 


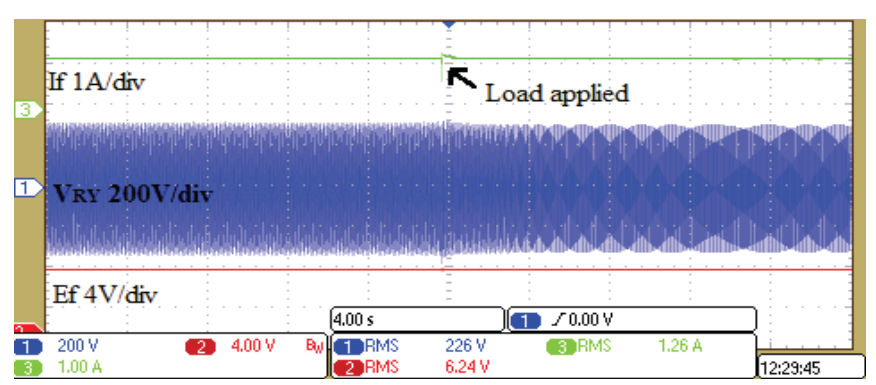

(a)

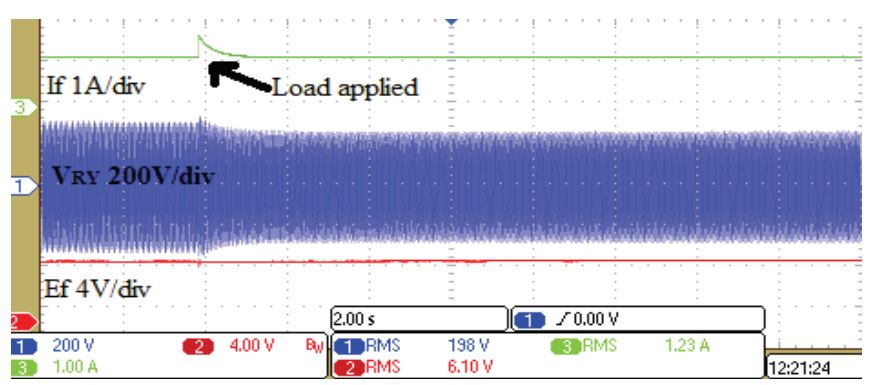

(b)

Fig. 13: Sudden application of load (a) 500W+120Var (capacitive) load, (b) 1000W unity pf load

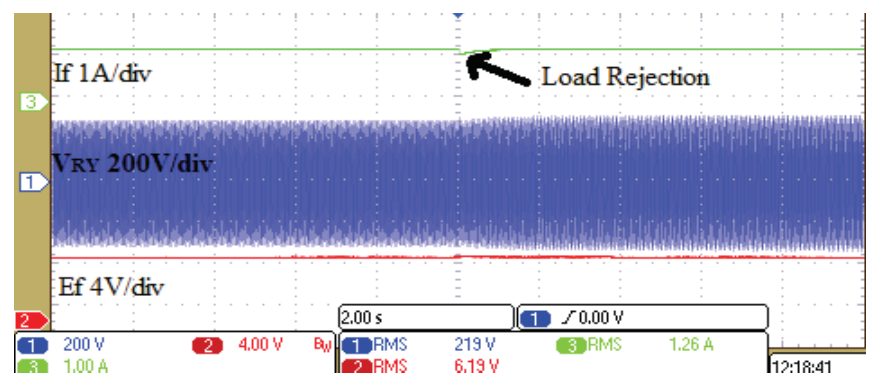

(a)

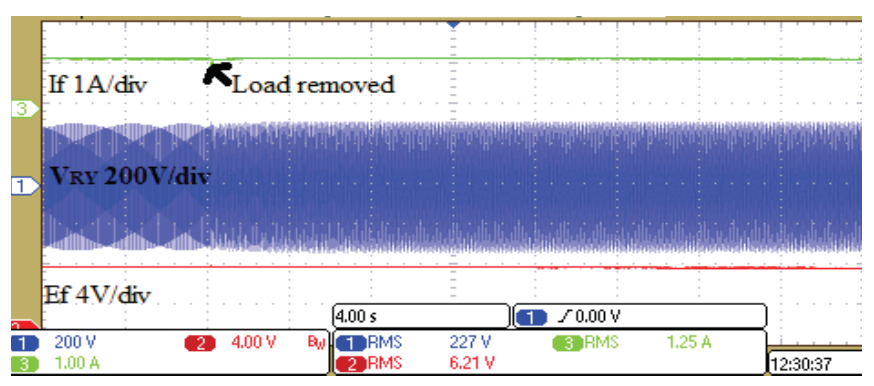

(b)

Fig. 14: Load rejection (a) 500W unity pf load, (b) 500W+120 Var (capacitive) load.

Initially, alternator was operating at the stable condition with line to line terminal voltage of $220 \mathrm{~V}$ with $500 \mathrm{~W}$ unity pf load. Then the load was disconnected completely and alternator got un-loaded as shown in Fig. 14a, the terminal voltages rose to $223 \mathrm{~V}$ and further achieved the steady state value of $219 \mathrm{~V}$. In the second case, alternator was initially loaded with $500 \mathrm{~W}+120 \mathrm{Var}$ (capacitive) operating at line to line terminal voltage of $220 \mathrm{~V}$. When the load was rejected completely, the phase variation in the line to line terminal voltage was observed with voltage shooting up to $227 \mathrm{~V}$ at the time of rejection and it further stabilized at $220 \mathrm{~V}$ as shown in Fig. 14b.

TABLE I: Exciter Parameters

\begin{tabular}{|l|l|}
\hline Input AC voltage & $400 / 220 \mathrm{~V}$ \\
\hline DC link Voltage $\mathrm{Vg}$ & $60 \mathrm{~V}$ \\
\hline Filter Inductor $(\mathrm{L})$ & $3.7 \mathrm{mH}$ \\
\hline Filter capacitor $(\mathrm{C})$ & $4700 \mu \mathrm{F}$ \\
\hline Switching Frequency & $5 \mathrm{kHz}$ \\
\hline PWM levels & $(0-15) \mathrm{V}$ \\
\hline Proportional constant $\left(K_{p}\right)$ & 0.0006325 \\
\hline Integral Constant $\left(K_{i}\right)$ & 0.003269 \\
\hline
\end{tabular}

TABLE II: Alternator Parameter

\begin{tabular}{|l|l|}
\hline Rated Terminal Voltage & $220 \mathrm{~V}$ \\
\hline Rated Field Voltage & $7.5 \mathrm{~V}$ \\
\hline Open Circuit d-axis Time constant $T_{d o}^{\prime}$ & $0.5775 \mathrm{~s}$ \\
\hline Rated armature current & $7.9 \mathrm{~A}$ \\
\hline Rated Speed & $1500 \mathrm{rpm}$ \\
\hline Rated input mechanical Power & $5.57 \mathrm{~kW}$ \\
\hline
\end{tabular}

\section{CONCLUSION}

The buck converter based static excitation system is proposed with field forcing capability under abnormal conditions and proper load regulation under steady state. The proposed system can replace the boost-buck converter based static excitation system with faster response. The performance has been found to meet IEEE 421.2.

\section{REFERENCES}

[1] IEEE standard definitions for excitation systems for synchronous machines, IEEE std 421.1, 2007.

[2] L.M. Domeratzky, A.S.Rubenstein, M.Temoshok, "A static excitation system for industrial and utility steam turbine generator", Transactions of the American Institute of Electrical Engineers. Part III: Power Apparatus and Systems, Vol. 80, Issue: 3 , April 1961.

[3] R.C. Schaefer, "Applying static excitation system", IEEE Industry Applications Magazine November/December 1998, pp 41-49.

[4] Francisco P. Demello, Charles Concordia,"Concepts of Synchronous Machine Stability as Affected by Excitation Control", IEEE Trans. on power apparatus and systems, vol.pas-88, no. 4, april 1969.

[5] Zhu Chen, Chengxiong Mao, Dan Wang, Jiming Lu, Yuhao Zhou, "Design and implementation of voltage source converter excitation system to improve power system stability", IEEE Trans. on industry application, vol. 52, No. 4, July/Aug 2016.

[6] Joseph B. Devotta, "A Dynamic model of the synchronous generator excitation control system", IEEE Trans. on industrial electronics, vol. ie-34, no.4, nov 1987.

[7] R. Hong-Woo, S. Seung-ki, and M. H. Park, "A new generator static excitation system using boost-buck chopper" Proc. 22nd Int. Conf. IEEE Ind. Electron. control instrun., 1996, pp. 1023-1028.

[8] M. J. Gibbard, P. Pourbek, and D. J. Vowles, "Small-signal stability, control and dynamic performance of power systems". University of Adelaide press, 2015. vol. 2. Oxford: Clarendon, 1892, pp.68-73.

[9] Robert W. Erickson, Dragan Maksimovic, "fundamentals of power electronics".

[10] K. Kim, R. Schaefer, "Tuning a PID controller for a digital excitation control system", IEEE Trans. Ind. Appl. vol. 41,no.2, 2005 485-492.

[11] IEEE guide for identification, testing, and evaluation of the dynamic performance of excitation system control, IEEE std 421.2, 2014.

[12] IEEE recommended practice for excitation system models for power system Stability Studies, IEEE std 421.5, 2016. 